\title{
Neuronal potassium channel openers in the management of epilepsy: role and potential of retigabine
}

This article was published in the following Dove Press journal:

Clinical Pharmacology: Advances and Applications

7 December 2010

Number of times this article has been viewed

\author{
Vincenzo Barrese' \\ Francesco Miceli $^{2}$ \\ Maria Virginia Soldovieri ${ }^{3}$ \\ Paolo Ambrosino 3 \\ Fabio Arturo lannotti ${ }^{3}$ \\ Maria Roberta Cilio ${ }^{2}$ \\ Maurizio Taglialatela ${ }^{1,3}$ \\ 'Department of Neuroscience, \\ University of Naples Federico II, \\ Naples; ${ }^{2}$ Division of Neurology, \\ IRCCS Bambino Gesù Children's \\ Hospital, Rome; ${ }^{3}$ Department of \\ Health Science, University of Molise. \\ Campobasso, Italy
}

\begin{abstract}
Despite the availability of over 20 antiepileptic drugs, about $30 \%$ of epileptic patients do not achieve seizure control. Thus, identification of additional molecules targeting novel molecular mechanisms is a primary effort in today's antiepileptic drug research. This paper reviews the pharmacological development of retigabine, an antiepileptic drug with a novel mechanism of action, namely the activation of voltage-gated potassium channels of the Kv7 subfamily. These channels, which act as widespread regulators of intrinsic neuronal excitability and of neurotransmitter-induced network excitability changes, are currently viewed among the most promising targets for anticonvulsant pharmacotherapy. In particular, the present work reviews the pathophysiological role of Kv7 channels in neuronal function, the molecular mechanisms involved in the Kv7 channel-opening action of retigabine, the activity of retigabine in preclinical in vitro and in vivo studies predictive of anticonvulsant activities, and the clinical status of development for this drug as an add-on treatment for pharmacoresistant epilepsy. Particular efforts are devoted to highlighting the potential advantages and disadvantages of retigabine when compared with currently available compounds, in order to provide a comprehensive assessment of its role in therapy for treatment-resistant epilepsies.
\end{abstract}

Keywords: epilepsy, retigabine, potassium channels, antiepileptic drugs, Kv7 channels

\section{Introduction}

Epilepsy is a disorder characterized by seizures due to recurrent, spontaneous episodes of aberrant synchronization in neuronal networks. ${ }^{1}$ It is the most common human neurologic disorder, with about 50 million people affected worldwide, an estimated prevalence of about $0.4 \%-1.0 \%$, and an estimated incidence of 20-70 new cases/10.000 individuals. ${ }^{2,3}$

Aberrant neuronal synchronization in epilepsy can remain focal, spread to other sites, or engage all cortical regions simultaneously. According to the most recent International League Against Epilepsy (ILAE) classification, epileptic seizures can be classified as generalized or partial. ${ }^{4}$ Generalized epileptic seizures engage bilaterally distributed networks which can include cortical and subcortical structures, but do not necessarily include the entire cortex and can be asymmetric. On the other hand, focal epileptic seizures originate within networks limited to one hemisphere, may be discretely localized or more widely distributed, and may originate in subcortical structures. The latest classification of the ILAE provides new concepts for the current understanding of epilepsies focusing on basic neurobiologic mechanisms rather than the clinical manifestations of the disease.
Correspondence: Maurizio Taglialatela Department of Health Sciences, Faculty of Health Sciences, University of Molise, Via De Sanctis, 86100 Campobasso, Italy $\mathrm{Tel}+39087440485 \mathrm{I}$

Fax +390874404763

Email m.taglialatela@unimol.it 
Except for a minority of cases which can be approached surgically, epilepsy treatment relies on the use of antiepileptic drugs to achieve symptomatic seizure control. Over 20 antiepileptic drugs, each with exquisite pharmacokinetics, spectrum of antiepileptic activity, and toxicity are currently available for this purpose. The mechanisms of action of most currently available antiepileptic drugs is restricted to voltage-gated sodium channels (phenytoin, carbamazepine), components of the $\gamma$-aminobutyric acid (GABA) system, including: $\mathrm{GABA}_{\mathrm{A}}$ receptors (phenobarbital, benzodiazepines), the GAT-1 GABA transporter (tiagabine), and GABA transaminase (vigabatrin); voltage-gated calcium channels (valproate, ethosuximide); and synaptic proteins involved in neurotransmitter release, such as SV2A (levetiracetam, brivaracetam).

Despite such a wide therapeutic armamentarium, it is currently estimated that about $30 \%$ of epileptic patients do not receive satisfactory treatment; this figure is even higher if one considers partial epilepsies in which developmental alterations leading to identifiable changes in brain structure are primary underlying causes. Thus, to improve some of the well known limitations of current anticonvulsant treatment, one of the most ambitious goals in today's antiepileptic research is the identification of additional molecules targeting novel molecular mechanisms involved in neuronal excitability control. The present paper reviews the preclinical and clinical development of retigabine, a novel antiepileptic drug targeting voltage-gated potassium $\left(\mathrm{K}^{+}\right)$ channels of the Kv7 subfamily. These channels, by acting as widespread regulators of intrinsic neuronal excitability and of neurotransmitter-induced network excitability changes, are currently viewed among the most promising "druggable" targets for anticonvulsant pharmacotherapy.

\section{Neuronal potassium channels of the Kv7 subfamily}

Potassium channels with distinct subcellular localization, biophysical properties, modulation, and pharmacologic profile are primary regulators of intrinsic electrical properties of neurons and their responsiveness to synaptic inputs. ${ }^{5}$ An increase in membrane conductance to $\mathrm{K}^{+}$ions causes neuronal hyperpolarization and, in most cases, reduces firing frequency, exerting a strong inhibitory function on neuronal excitability.

Among voltage-gated $\mathrm{K}^{+}$currents, the $\mathrm{M}$-current $\left(\mathrm{I}_{\mathrm{KM}}\right)$ is a primary transducer of changes in the extracellular chemical composition into modification of the intrinsic neuronal properties. $\mathrm{I}_{\mathrm{KM}}$ was first identified in amphibian peripheral neurons ${ }^{6}$ but later found to be widely distributed also in the mammalian peripheral and central nervous system. ${ }^{7} \mathrm{I}_{\mathrm{KM}}$ is a low-threshold, slowly activating and deactivating, and noninactivating voltage-dependent $\mathrm{K}^{+}$current which limits repetitive firing and causes spike frequency adaptation. ${ }^{8}$ Activation of several receptors linked to pertussis toxin-insensitive $G$ proteins of the $G_{q / 11}$ family, including $M_{1}, M_{3}$, and $\mathrm{M}_{5}$ subtypes of muscarinic receptors (hence its definition), ${ }^{9}$ can control neuronal excitability by suppressing $\mathrm{I}_{\mathrm{KM}} \cdot{ }^{10,11}$

The identification of the molecular basis of $I_{K M}$ was achieved in the late 1990s upon the discovery that benign familial neonatal seizures, a rare autosomal dominant idiopathic epilepsy of the newborn characterized by the occurrence of focal or generalized seizures starting around day 3 of postnatal life and spontaneously disappearing after few weeks or months, was associated with mutations in $\mathrm{Kv} 7.2^{12,13}$ or, more rarely, Kv7.3, ${ }^{14}$ both genes encoding for $\mathrm{K}^{+}$channel subunits.

Kv7.2 and Kv7.3 belong to the Kv7 (KCNQ) subfamily of $\mathrm{K}^{+}$channel genes. This subfamily is composed of five members, also including Kv7.1 which is expressed in several non-neuronal tissues including the heart, where it underlies the $I_{\mathrm{Ks}}$ current involved in the late repolarization phase of the cardiac action potential, ${ }^{15}$ and in epithelial cells of several organs; Kv7.4, which is expressed in primary sensory cells in the inner ear and in neurons of the central auditory pathway, ${ }^{16,17}$ as well as in skeletal muscle, ${ }^{18}$ and visceral and vascular smooth muscle; ${ }^{19}$ and Kv7.5, whose transcripts have been detected in the brain, as well as in skeletal and smooth muscle cells. ${ }^{20}$ Because of their expression in the nervous system, Kv7.2-Kv7.5 subunits are commonly referred to as "neural" Kv7 subunits. ${ }^{21}$

Most of the biophysical and pharmacologic properties of $\mathrm{I}_{\mathrm{KM}}$ in neurons are recapitulated upon heteromeric expression of Kv7.2 and Kv7.3 subunits. ${ }^{22,23}$ Functional studies in heterologous expression systems revealed that mutations in Kv7.2 and Kv7.3 genes causing benign familial neonatal seizures decrease the ability of $\mathrm{I}_{\mathrm{KM}}$ to suppress neuronal excitability. ${ }^{24}$

Genetically-modified animal models further confirmed the specific involvement of Kv7.2 and Kv7.3 in brain excitability control. Heterozygous mice carrying a targeted deletion of the Kv7.2 gene displayed an increased sensitivity to proconvulsant stimuli. ${ }^{25}$ In addition, transgenic mice conditionally expressing mutant Kv7.2 subunits causing dominant-negative suppression of $\mathrm{I}_{\mathrm{KM}}$ function showed signs of increased neuronal excitability in hippocampal CA1 pyramidal neurons, spontaneous seizures, behavioral hyperactivity, and deficits 
in hippocampus-dependent spatial memory. ${ }^{26} \mathrm{~A}$ third model of Kv7.2 deficiency is represented by stzl mice carrying an ethylnitrosurea-induced deletion of a large genomic region encompassing Kv7.2; heterozygous stz1 mice, similar to Kv7.2 knockout mice, have a reduced electroconvulsive threshold and an increased sensitivity to the convulsant pentylenetetrazole, together with structural abnormalities in the hippocampal formation. ${ }^{27}$ More recently, mouse models carrying missense mutations that underlie human benign familial neonatal seizures into the orthologous murine Kv7.2 and Kv7.3 genes have been established. While heterozygous mice exhibited reduced thresholds to electrically induced seizures compared with wild-type littermate mice, homozygous mutant mice showed early-onset spontaneous generalized tonic-clonic seizures that triggered neuronal plasticity without hippocampal mossy fiber sprouting. ${ }^{28}$

\section{Kv7 channel openers: retigabine and novel mechanism of action of anticonvulsants Potential role of $I_{\text {KM }}$ openers}

Given the previously mentioned functional and genetic evidence, activation of neuronal $\mathrm{I}_{\mathrm{KM}}$ is currently considered as a primary strategy for pharmacologic intervention in epilepsy and other human diseases, such as migraine and chronic pain, all conditions in which neuronal hyperexcitability appears to play a fundamental pathogenetic role. In all these diseases, hyperpolarization of the resting membrane potential and decreased action potential generation, prompted by the activation of neuronal $\mathrm{K}^{+}$currents in excitatory neurons, may result in an effective therapeutic strategy. As a matter of fact, compounds with $\mathrm{I}_{\mathrm{KM}}$ opening abilities have undergone extensive preclinical and clinical investigation as potential antiepileptics and analgesics, even before their molecular mechanism of action was discovered.

\section{History of retigabine}

Retigabine (D-23129, chemical name N-(2-amino-4(4-fluorobenzylamino)-phenyl)-carbamic acid ethyl ester) is the prototype $\mathrm{I}_{\mathrm{KM}}$ opener. Retigabine is a structural analog of flupirtine (D-9998), a triaminopyridine successfully used in clinical practice in some European countries since 1984 as a centrally acting nonopioid analgesic, also provided with muscle relaxant and neuroprotective actions, ${ }^{29,30}$ but devoid of appreciable anti-inflammatory and antipyretic activity. ${ }^{31}$

In the Antiepileptic Drug Development program supported by the US National Institutes of Health using in vivo animal screening strategies, flupirtine was shown in the late 1980s to have anticonvulsant activity, although at doses higher than those producing analgesia. Structure-activity optimization of flupirtine yielded retigabine, which showed more effective anticonvulsant activity when compared with flupirtine, being active in nearly every animal seizure model, with an overall profile different from any other known drug. ${ }^{32}$ The broad profile of efficacy in animal models already suggested that the mechanism(s) involved in the anticonvulsant actions of retigabine were distinct from those previously known. In the late $1990 \mathrm{~s}$, retigabine was shown to activate voltage-dependent neuronal $\mathrm{K}^{+}$currents at concentrations at least 10-30 times lower than those producing a potentiation of $\mathrm{GABA}_{\mathrm{A}}$-mediated currents and a weak blocking action on ligand- (kainate and NMDA receptors) and voltage-gated (sodium and calcium) channels. ${ }^{33,34}$ However, these studies failed to identify the precise nature of the $\mathrm{K}^{+}$current targeted by retigabine; this was only possible when drug effects were evaluated on native $\mathrm{I}_{\mathrm{KM}}$ in neuronal cells and on cloned Kv7.2 and Kv7.3 channels in heterologous expression systems; these experiments, clearly demonstrated that $\mathrm{I}_{\mathrm{KM}}$ formed by $\mathrm{Kv} 7.2 / 3$ subunits was the major molecular target for retigabine. ${ }^{35-37}$ In addition to $\mathrm{I}_{\mathrm{KM}}$ opening, both retigabine and flupirtine have been shown to possess antioxidant properties in vitro, ${ }^{29,38}$ a pharmacological property which might explain at least some of the neuroprotective effects shown by both compounds.

\section{Mechanism of action of retigabine}

The biophysical mechanism responsible for retigabine-induced $\mathrm{I}_{\mathrm{KM}}$ potentiation is rather complex, and involves a combination of two factors, ie, a hyperpolarizing shift in the voltagedependence of the channel activation process and an increase in the maximal opening probability of these channels. Both these effects can contribute by a variable amount in channels formed by different combinations of Kv7 subunits. In fact, the hyperpolarizing shift is maximal for Kv7.3 $(-43 \mathrm{mV})$, intermediate for Kv7.2 (-24 mV), smaller for Kv7.4 (-14 mV), and absent for Kv7.5 homomeric channels. ${ }^{39,40}$ In Kv7.5 channels, instead, retigabine markedly increases the current irrespective of the membrane potential; by contrast, in Kv7.2 and Kv7.2/3 combinations, the maximal amount of current elicited by strong depolarization is not affected, whereas homomeric Kv7.4 channels show both the shift in voltage-dependent opening probability and an increase in maximal conductance. ${ }^{39}$ These changes are accompanied by a variable degree of drug-induced delay in channel closure (deactivation), suggesting that the primary molecular consequence of the interaction of retigabine with the channel protein is a stabilization of the channel pore in the open conformation. 
Retigabine-induced enhancement of $\mathrm{I}_{\mathrm{KM}}$ hyperpolarizes the neuronal resting membrane potential, leading to an inhibition of spontaneous or synaptically-triggered neuronal activity. Intriguingly, some mutations causing benign familial neonatal seizures in Kv7.2 prompt functional changes in $\mathrm{I}_{\mathrm{KM}}$ biophysical properties which are opposite to those caused by retigabine. ${ }^{41}$ As previously mentioned, retigabine affects $I_{K M}$ underlined by all different Kv7 subunits. However, the potency of retigabine in causing activation of the channels formed by distinct Kv7 subunits appears slightly different, with, in most cases, Kv7.2 and Kv7.3 showing higher $\left(\mathrm{EC}_{50}<1 \mu \mathrm{M}\right)$ and $\mathrm{Kv} 7.4$ and Kv7.5 lower $\left(\mathrm{EC}_{50}>1 \mu \mathrm{M}\right)$ sensitivity to the drug. Nevertheless, because these differences are quantitatively rather small, retigabine is currently regarded as a "nonselective" neural Kv7 channel opener. Noticeably, none of these actions are prompted by retigabine in cardiac Kv7.1 channels, an important observation to interpret the lack of cardiac toxicity shown by this compound.

\section{Other $I_{K M}$ activators}

The described results firmly establish $\mathrm{I}_{\mathrm{KM}}$ as a crucial target for pharmacological intervention in hyperexcitability diseases, and have led to an explosion of interest in the identification of congeners additional to flupirtine and retigabine acting as $\mathrm{I}_{\mathrm{KM}}$ activators. Among these, phenamates, such as meclofenamic acid and diclofenac, well known blockers of the cyclooxygenase enzymes, have been described to act as Kv7.2/3 $\mathrm{K}^{+}$channel openers and to show robust antiepileptic properties in vivo. ${ }^{42}$ Although these pharmacological actions require rather high drug concentrations, these compounds have been suggested to represent novel drug templates for the treatment of neuronal hyperexcitability diseases, including epilepsy, migraine, or neuropathic pain. Indeed, more recent studies demonstrated that diclofenac derivatives with poor (NH6) ${ }^{43}$ or absent (NH29) ${ }^{44}$ cyclooxygenase-blocking activity reduced neuronal excitability and/or showed anticonvulsant effects in murine models of seizures.

The interest in $\mathrm{I}_{\mathrm{KM}}$ (and in particular in Kv7.2/3 subunits) as a possible target in the treatment of epilepsy and other hyperexcitability diseases has also led to the development of ICA-27243, a compound belonging to the chemical class of substituted benzamides. In contrast with retigabine, which does not discriminate between channels formed by different Kv7 subunits, ICA-27243 showed high selectivity for current elicited by Kv7.2/Kv7.3 heterotetramers, with an $\mathrm{EC}_{50}$ of $0.4 \mu \mathrm{M}$, while its potency on Kv7.4 or Kv7.3/Kv7.5 channels was 20 -fold and $>100$-fold lower, respectively. ${ }^{45}$ Moreover, ICA-27243 exhibited anticonvulsant properties in preclinical models of seizures. ${ }^{46}$ The search for new molecules with agonistic activity on Kv7 channels prompted Xiong et al to demonstrate that zinc pyrithione is an activator of heterologous expressed and native $\mathrm{I}_{\mathrm{KM}} \cdot{ }^{47}$ Zinc pyrithione potentiated $\mathrm{K}^{+}$currents elicited both by cardiac Kv7.1 and neural Kv7.2-5 subunits, except those sustained by Kv7.3 channels; in addition, its agonistic action was noncompetitive with that exerted by retigabine, giving rise to combinatorial effects when applied together. ${ }^{48}$ Other molecules able to enhance Kv7-mediated current include BMS-204352, originally developed as an opener of $\mathrm{Ca}^{2+}$ - and voltagegated $\mathrm{K}^{+}$channels, and the acrylamide compound, (S)-1. Although both these molecules can open channels formed by all neural Kv7 subunits, they display a noticeably stronger action on channels formed by Kv7.4 subunits (BMS$204352)^{49,50}$ or on Kv7.4 and Kv7.5 subunits [(S)-1]. ${ }^{51}$

\section{The binding site for retigabine on neuronal Kv7 channels}

Results from mutagenesis and modeling experiments have suggested that, in channels formed by neural Kv7 subunits, retigabine binds to a hydrophobic pocket located between the cytoplasmic parts of the $\mathrm{S}_{5}$ and the $\mathrm{S}_{6}$ transmembrane domains in the open channel configuration. Within this cavity, a tryptophan residue in the intracellular end of the $\mathrm{S}_{5}$ helix (W236 in the Kv7.2 sequence) seems to play a crucial role..$^{52,53}$ Replacement of this residue with a smaller and less hydrophobic amino acid (leucine) largely prevents the ability of retigabine to activate $\mathrm{I}_{\mathrm{KM}}$. Additional amino acids (in Kv7.2 sequence: Leu243 in $\mathrm{S}_{5}$, Leu275 within the inner pore loop, Gly301 in the $\mathrm{S}_{6}$ segment, and Leu299 in $\mathrm{S}_{6}$ of the neighboring subunit) seem also to be involved in the formation of the complete retigabine binding site ${ }^{54}$ (see Figure 1). Except for Leu275, these amino acids are conserved among all neural Kv7 subunits but are missing in the Kv7.1 subunit primary sequence, an observation that may explain the lack of sensitivity to retigabine shown by channels formed by Kv7.1 subunits. The tryptophan in the $\mathrm{S}_{5}$ segment seems also to be important for the binding of other $\mathrm{I}_{\mathrm{KM}}$ activators, such as S-(1) and BMS-204352, both molecules failing to show additive effects with retigabine. ${ }^{51}$ Another Kv7 activator, zinc pyrithione, also seems to bind to the pore region, although the molecular determinants for such an interaction appear to be only partially overlapping with those of retigabine, a result consistent with the additive effects on $\mathrm{I}_{\mathrm{KM}}$ exerted by these two compounds. ${ }^{48}$ 


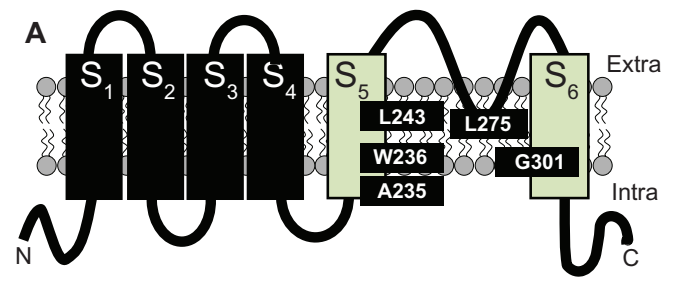

B
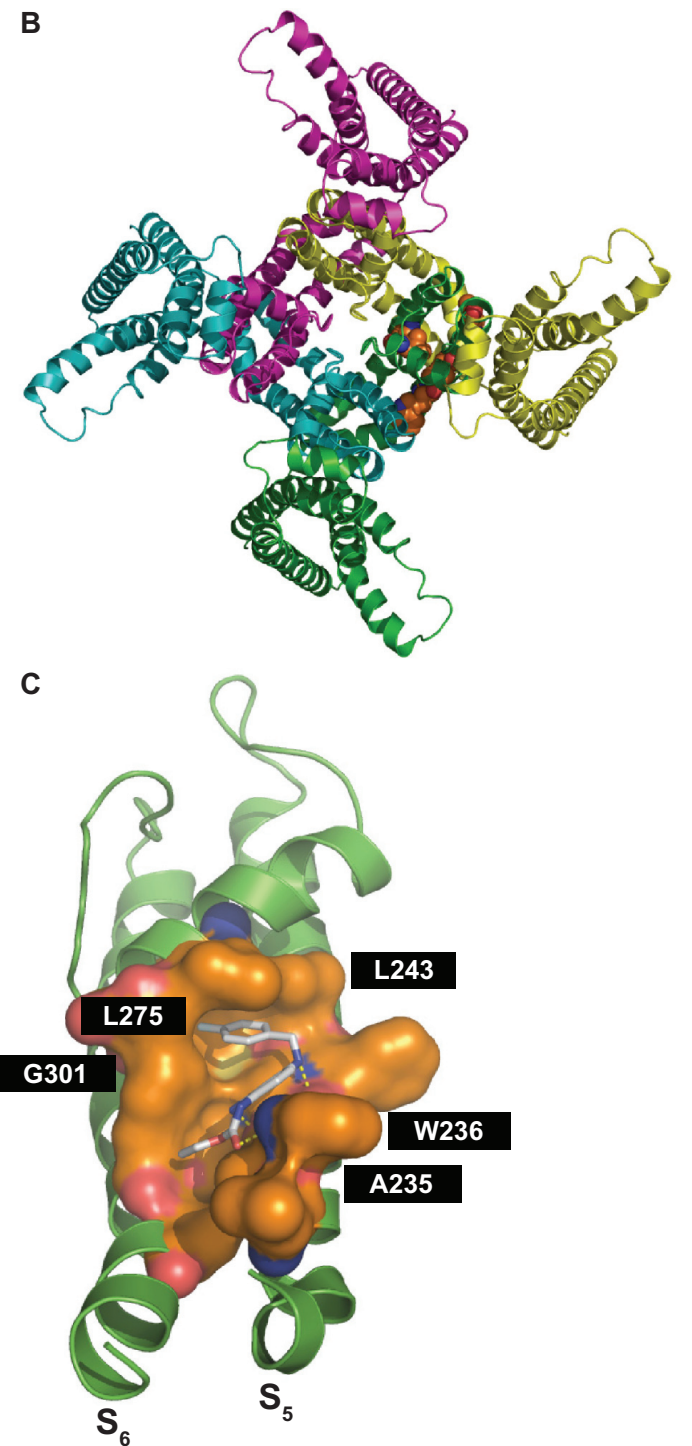

Figure I Panel A shows the schematic topology of a single Kv7.2 subunit, with each of the six transmembrane regions indicated. The green cylinders correspond to the $\mathrm{S}_{5}$ and $\mathrm{S}_{6}$ transmembrane regions. The amino acids involved in retigabine binding are indicated. Panel B shows a top view of the overall structure of the channel formed by four identical $\mathrm{K}_{\mathrm{v}} 7.2$ subunits, with one retigabine molecule bound. Panel $\mathrm{C}$ shows an enlarged view of the retigabine binding site with the retigabine molecule docked into the channel cavity as obtained with ArgusLab 4.0.I (Planaria Software LLC, Seattle, WA; available at http://www.arguslab.com). The residues involved in retigabine binding are indicated. The dashed yellow lines indicate the polar contacts between retigabine and the residues A235 and W236. Three-dimensional models of $\mathrm{K}_{\mathrm{\gamma}} 7.2$ subunits were generated by homology modelling using known structures of potassium channel subunits available in the Protein Data Bank), using SWISSMODEL, a program that performs automated sequence-structure comparisons, as previously described..$^{92}$ The model generated was analyzed using both the DeepView module of Swiss-PDBViewer (version 3.7, available at http://www.expasy.ch/spdbv/) and PyMOL (available at http://pymol.sourceforge.net/). In the present study, the homology model was built using the template structure $(2 \mathrm{R} 9 \mathrm{RH})$ for a chimeric channel in which the voltage-sensor paddle (corresponding to the $\mathrm{S}_{3 \mathrm{~b}}-\mathrm{S}_{4}$ region) of $\mathrm{K}_{\mathrm{v}} 2.1$ was transferred into the $\mathrm{K}_{\mathrm{v}} \mathrm{I} .2$ subunit. ${ }^{93}$
By contrast, phenamates (meclofenamic acid and diclofenac, as well as their derivatives) were still able to potentiate the $\mathrm{K}^{+}$currents elicited by the Kv7.2 W236L mutant, suggesting their preferential binding in a different domain of the channel. In fact, $\mathrm{NH} 29$ appears to bind in close proximity to the external surface of the voltage-sensing domain, at the interface of helices $\mathrm{S}_{1}, \mathrm{~S}_{2}$, and $\mathrm{S}_{4}$, with a mechanism of action similar to that of gating-modifier toxins. ${ }^{55}$ Similar to $\mathrm{NH} 29$, the selective $\operatorname{Kv} 7.2 / \mathrm{Kv} 7.3$ opener ICA-27243 was also found to bind to the voltage-sensing domain; the primary sequence of the region involved in ICA-27243 binding appears extremely variable among Kv7 subfamily members, allowing the drug to selectively affect channels formed by specific Kv7 subunits. ${ }^{56}$

In conclusion, the identification of the different regions on the channel molecule involved in binding distinct molecular entities might represent the starting point to design molecules selectively targeting strategic functional domains of Kv7 subunits, and may possibly allow for drug specificity at each Kv7 channel subtype. Whether this will translate into better efficacy and side effect profiles, and, therefore, into significant advantages for the treatment of hyperexcitability disorders with Kv7 channel openers, is still a matter of investigation.

\section{Retigabine in preclinical models predictive of anticonvulsant activity}

The therapeutic potential of retigabine as an antiepileptic drug has been assessed in several preclinical studies using various models. Retigabine was shown to be effective in reducing convulsions induced both by maximal electroshock (similarly to carbamazepine, phenytoin, and diazepam) and by pentylenetetrazole, picrotoxin, and NMDA (similarly to ethosuximide and valproate), two models predictive for drug efficacy in humans against generalized tonic-clonic, and generalized absence and myoclonic epilepsies, respectively. ${ }^{57}$ Moreover, retigabine has been also tested in genetic models of epilepsy, such as DBA/2 mice ${ }^{57}$ or epilepsy-prone rats (GEPR-3 and GEPR-9) ${ }^{58}$ ie, models possessing some predictability for generalized tonic-clonic seizures (DBA/2 mouse and GEPR-9 rat) and absence seizures (GEPR-3 rat). In these three rodent models, retigabine was able to reduce seizures induced by loud noise stimulation. In addition, in DBA/2 mice, it showed an additive effect when administered in combination with classical anticonvulsants, most notably diazepam, phenobarbital, phenytoin, and valproate. ${ }^{59}$ The administration of low doses of retigabine $(0.01 \mathrm{mg} / \mathrm{kg}$ intraperitoneally or orally) also increased the threshold for induction of afterdischarges in the amygdala-kindling model of complex partial seizures; at higher 
doses ( $5 \mathrm{mg} / \mathrm{kg}$ intraperitoneally or $15 \mathrm{mg} / \mathrm{kg}$ orally) it reduced seizure severity and duration, total duration of behavioral changes, and afterdischarge duration. The potency of retigabine was much higher when compared with that of valproate; moreover, the doses required to increase the seizure threshold in amygdala-kindled rats are substantially lower than those needed to increase the threshold in the maximal electroshock test (an effect opposite to that of carbamazepine, phenytoin, and valproate), suggesting that retigabine is particularly effective against partial seizures. ${ }^{60}$ Seizure models used in these studies lack specific predictivity against pharmacoresistant epilepsy. The fact that retigabine recognizes a molecular target distinct from currently available antiepileptic drugs makes this molecule particularly attractive for potential efficacy in drugresistant epilepsies. To address this possibility, retigabine has been tested in vivo in lamotrigine-resistant kindled rats ${ }^{61}$ and in the $6 \mathrm{~Hz}$ psychomotor mouse model, ${ }^{62}$ two preclinical models of epilepsy resistant to common antiepileptic drugs including lamotrigine, phenytoin, carbamazepine, topiramate, tiagabine, and felbamate. In these models, retigabine dose-dependently inhibited seizures and reduced afterdischarge duration induced by kindling stimulation and by $32 \mathrm{~mA}$ or $44 \mathrm{~mA}$ corneal stimulation, respectively. ${ }^{63}$ In addition, retigabine was shown to reduce spontaneous bursting in hippocampal-entorhinal cortex slices from kainate-treated rats resistant to therapeutic concentrations of phenytoin, carbamazepine, and valproate, ${ }^{64}$ and to suppress spontaneous spike waves and low magnesium induced-epileptiform field potential in neocortical slices prepared from human patients with pharmacoresistant epilepsy undergoing surgical treatment. ${ }^{65}$ In conclusion, retigabine showed activity in a broad array of in vitro and in vivo epilepsy models, including some in which classical antiepileptic drugs failed to be effective.

\section{Pharmacokinetics of retigabine in humans}

Studies carried out to investigate retigabine pharmacokinetics in both healthy volunteers and patients mostly gave concordant results. The bioavailability of orally administered retigabine is $60 \%$, with a very low first-pass metabolism. Absorption is rapid, and plasma peak concentration is achieved within 1.5 hours. Food does not significantly interfere with absorption of retigabine, causing only slight delays in the time required to reach plasma peak concentration (up to two hours). Retigabine plasma protein binding is about $80 \%$, and the drug is widely distributed, with a volume of distribution of approximately $6.2 \mathrm{~L} / \mathrm{kg}$. Retigabine is metabolized only by Phase II reactions, primarily by acetylation (to a monoacetylated metabolite known as AWD21-360, which has similar half-life but lower anticonvulsant potency when compared with retigabine) and glucuronidation (via UGT1A1, A3, A4, and A9). Glucuronidation (which also occurs for AWD21-360) leads to the formation mainly of $\mathrm{N}_{2}$ - and of a minor amount of $\mathrm{N}_{4}$-glucuronide, both possessing no antiepileptic activity. Of note, Phase I clinical studies pointed to a constant ratio between retigabine and the $\mathrm{N}_{2}$-glucuronide metabolite, suggesting that the two compounds are coupled via enterohepatic circulation and glucuronidation/deglucuronidation reactions occurring in the liver and gut, respectively. ${ }^{66}$ Retigabine does not induce or inhibit its own metabolism, and is eliminated primarily by the kidneys, with a mean terminal half-life of 8.0 hours and an apparent oral clearance of $0.70 \mathrm{~L} / \mathrm{h} / \mathrm{kg}$. The pharmacokinetics of retigabine are linearly proportional to the dose. Steady-state pharmacokinetics were in agreement with single-dose pharmacokinetics, and the accumulation ratio was about $1.5 .{ }^{67}$ Only a few differences regarding race, gender, and age have been observed in pharmacokinetic parameters. Ferron et al reported lower clearance and volume of distribution for retigabine in black subjects (25\% and 30\% lower, respectively), possibly due to differences in $\mathrm{N}$-glucuronidation. In another study, retigabine was found to reach higher maximum concentration $(56 \%)$ and exposure $(20 \%)$ in young women when compared with young men, but showed similar clearance; this variability likely reflected differences in body weight. In elderly subjects, retigabine elimination was slower (30\% lower apparent clearance normalized for weight), resulting in higher exposure $(42 \%)$ and longer half-life (30\%), although maximum concentration was similar to that in adults. These differences have been attributed to the decline of renal function with age ${ }^{68}$ No significant alterations in tolerability and safety were found in subjects with polymorphisms in the UGT1A1 (ie, Gilbert's syndrome) and/or in N-acetyltransferase, NAT2 (ie, fast or slow acetylator) after a single and multiple (twice daily) $200 \mathrm{mg}$ dose of oral retigabine administered over five days, although the total exposure to the monoacetylated metabolite, AWD21-360, was significantly related to the fast or slow acetylator status of subjects. ${ }^{69}$ In vitro assays in human liver microsomal preparations showed that $6 \mu \mathrm{M}$ retigabine (a concentration similar to the peak concentration in subjects receiving a therapeutic dose of the drug) has a moderate capacity to inhibit cytochrome (CYP)2A6 and low or no potential to inhibit CYP1A2, CYP2C8/9/19, CYP2D6, CYP2E1, CYP3A4/5, and CYP4A9/11. According to these studies, no clinically relevant inhibition of CYP-mediated drug metabolism is expected. The potential for drug-drug interaction due 
to competition for glucuronidation was investigated using valproic acid, lamotrigine, imipramine, and propofol, commonly used medications which are extensively glucuronidated. When assayed with human liver microsomes or UGT1 A9 enzyme, no interactions were found at clinically relevant concentrations. ${ }^{70}$ Moreover, no clinically significant interactions between retigabine and phenobarbital were reported in clinical studies in healthy subjects. ${ }^{71}$ By contrast, patients already treated with phenytoin and carbamazepine (two drugs known to induce UGT enzymes) showed an increased clearance of retigabine by $36 \%$ and $27 \%$, respectively. Valproate and topiramate coadministration did not modify retigabine pharmacokinetics. Retigabine did not alter the pharmacokinetic profile of phenytoin, carbamazepine, valproate, phenobarbital, and topiramate. ${ }^{72}$ Although in this latter study no significant interactions were observed in patients receiving retigabine in addition to lamotrigine, Hermann et al reported a modest reciprocal pharmacokinetic interaction between these two antiepileptic drugs; lamotrigine reduced the clearance of retigabine by $13 \%$, while it increased the mean half-life and the area under the plasma concentration-time curve (AUC) by $7.5 \%$ and $15 \%$, respectively. Retigabine also influenced lamotrigine pharmacokinetics, by increasing its clearance (by $22 \%$ ) and reducing its mean half-life (by 15\%) and AUC (by $18 \%) .{ }^{73}$ While the reduced clearance of retigabine induced by lamotrigine is explained by the authors as competition for renal excretion, the effect of retigabine on lamotrigine pharmacokinetics remains unclear, because retigabine did not show enzyme induction in various other drug-drug interaction studies. Retigabine did not decrease contraceptive hormone exposure in women taking a low-dose oral contraceptive (ethinyl estradiol $0.035 \mathrm{mg}$ + norethindrone $1 \mathrm{mg}$ ), suggesting no potential for reducing contraceptive efficacy. Moreover, the AUC values of retigabine measured in women receiving such combination therapy were not significantly different from those reported in other studies, suggesting that oral contraceptives did not alter retigabine pharmacokinetics. ${ }^{72}$

\section{Efficacy studies with retigabine}

Retigabine efficacy in the treatment of partial onset seizures has been assessed by multicenter, randomized, double-blind, placebo-controlled Phase II and Phase III clinical trials (Table 1).

\section{Phase II studies}

A Phase II study ${ }^{74,75}$ was conducted to evaluate the 16-week (eight-week titration phase, eight-week maintenance phase) efficacy and safety of retigabine 600, 900, and $1200 \mathrm{mg}$ /day (divided into three daily doses) versus placebo as an adjunctive therapy in partial onset seizures. Patients enrolled in this trial $(n=396)$ were men and women 16-70 years of age, with incomplete control of seizures despite therapy with 1-2 antiepileptic drugs or vagal nerve stimulation treatment (considered as an antiepileptic drug if stimulation parameters were kept constant during the study), which did not have to be discontinued throughout the study. Patients had to experience at least four partial onset seizures per month (with or without secondary generalization) in the eight-week baseline period, and no 30-day seizure-free period. The results of this study showed that retigabine caused a significant and dose-dependent reduction in median percent monthly seizure frequency from baseline by $23 \%$ (600 $\mathrm{mg} /$ day), by $29 \%$ (900 mg/day), and by 35\% (1200 mg/day); in the placebo group the reduction was by $13 \%$. The responders rates (patients with $\geq 50 \%$ seizure frequency reduction) were $23 \%$, $32 \%$, and $33 \%$ in the 600,900 , and $1200 \mathrm{mg} /$ day groups, respectively, versus $16 \%$ in the placebo arm). It is interesting to note that the difference between the $600 \mathrm{mg} /$ day arm and placebo group was not statistically significant. A total of 222 patients who completed the double-blind 16-week trial entered an open-label extension study, in which the retigabine dose was converted to $900 \mathrm{mg} /$ day. Following this, each patient's daily dose of retigabine or concomitant antiepileptic drugs could be either reduced or increased up to a maximum allowed dose of $1200 \mathrm{mg}$ retigabine. The median decrease in monthly total partial seizure frequency from baseline was $48.3 \%$ and the responders rate was $46.4 \%{ }^{72,76}$

\section{Phase III studies}

Based on the positive results of the Phase II study, two multicenter, double-blind, placebo-controlled Phase III registration trials investigating the efficacy of retigabine as add-on therapy in the treatment of refractory partial onset epilepsy, called RESTORE 1 and RESTORE 2, have been performed and recently completed. Patients enrolled in these two studies showed similar clinical features to those of the Phase II clinical trial (18-75 years of age, partial onset epilepsy with or without secondary generalization, refractory to stable therapy with 1-3 approved antiepileptic drugs, $\geq$ four seizures per month and no 21-day seizure-free period during the eight-week baseline period), but differed in the target dosage and titration phase duration. In RESTORE 1, the target dose of retigabine was $1200 \mathrm{mg}$ /day titrated over six weeks and with dosage adjustment allowed (to a minimum of $1050 \mathrm{mg} /$ day); in RESTORE 2, retigabine 600 and $900 \mathrm{mg} /$ day were administered, titrated over 2-4 weeks and 
Table I Summary of Phase II and Phase III clinical trials with retigabine

\begin{tabular}{|c|c|c|c|}
\hline & \multirow{2}{*}{$\begin{array}{l}\text { Phase II } \\
\text { Study } 205\end{array}$} & \multicolumn{2}{|l|}{ Phase III } \\
\hline & & Study 30 I (RESTORE I) & Study 302 (RESTORE 2) \\
\hline Patients & $\begin{array}{l}\text { Age: I6-70 years } \\
\text { Gender: men and women } \\
\text { Clinical features: partial onset } \\
\text { epilepsy ( } \geq 4 \text { seizures/month; } \\
\text { no } 30 \text {-day seizure-free period } \\
\text { in the baseline period) } \\
\text { Concomitant therapy: I-2 standard } \\
\text { AEDs (VP, CMZ, PHT, TPR, } \\
\text { LMT, GBP); VNS }\end{array}$ & $\begin{array}{l}\text { Age: } 18-75 \text { years } \\
\text { Gender: men and women } \\
\text { Clinical features: partial onset } \\
\text { epilepsy ( } \geq 4 \text { seizures/month; } \\
\text { no } 2 \text { I-day seizure-free period in } \\
\text { the baseline period) } \\
\text { Concomitant therapy: I-3 standard } \\
\text { AEDs (VP, CMZ, PHT, TPR, } \\
\text { LMT, GBP); VNS }\end{array}$ & $\begin{array}{l}\text { Age: I8-75 years } \\
\text { Gender: men and women } \\
\text { Clinical features: partial onset } \\
\text { epilepsy ( } \geq 4 \text { seizures/month; } \\
\text { no } 2 \text { I-day seizure-free period in } \\
\text { the baseline period) } \\
\text { Concomitant therapy: } \\
\text { I-3 standard AEDs (VP, CMZ, } \\
\text { PHT, TPR, LMT, GBP); VNS }\end{array}$ \\
\hline Patients (n) & 396 & 256 & $47 \mid$ \\
\hline Dose of RT & $\begin{array}{l}1200 \mathrm{mg} / \text { day }(400 \mathrm{mg} \mathrm{tid}) \\
900 \mathrm{mg} / \text { day }(300 \mathrm{mg} \mathrm{tid}) \\
600 \mathrm{mg} / \text { day }(200 \mathrm{mg} \mathrm{tid}) \\
\text { No change of dose allowed }\end{array}$ & $\begin{array}{l}1200 \mathrm{mg} / \text { day ( } 400 \mathrm{mg} \text { tid) } \\
\text { Dose reduction allowed } \\
\text { (to } 1050 \mathrm{mg} / \text { day) }\end{array}$ & $\begin{array}{l}900 \mathrm{mg} / \text { day }(300 \mathrm{mg} \mathrm{tid}) \\
600 \mathrm{mg} / \text { day }(200 \mathrm{mg} \text { tid }) \\
\text { No change of dose allowed }\end{array}$ \\
\hline Study design & $\begin{array}{l}\text { 8-week baseline period } \\
\text { 8-week forced titration period } \\
\text { 8-week maintenance period }\end{array}$ & $\begin{array}{l}\text { 8-week baseline period } \\
\text { 6-week forced titration period } \\
\text { 12-week maintenance period }\end{array}$ & $\begin{array}{l}\text { 8-week baseline period } \\
\text { 4-week forced titration period } \\
\text { I2-week maintenance period }\end{array}$ \\
\hline $\begin{array}{l}\text { Median seizure } \\
\text { frequency reduction }\end{array}$ & $\begin{array}{l}23 \% \text { in } 600 \mathrm{mg} / \text { day RT arm* } \\
29 \% \text { in } 900 \mathrm{mg} / \text { day RT arm } \\
35 \% \text { in } 1200 \mathrm{mg} / \text { day RT arm } \\
13 \% \text { in placebo arm }\end{array}$ & $\begin{array}{l}44 \% \text { in } \mathrm{RT} \text { arm } \\
17.5 \% \text { in placebo arm }\end{array}$ & $\begin{array}{l}27.9 \% \text { in } 600 \mathrm{mg} / \text { day RT arm } \\
39.9 \% \text { in } 900 \mathrm{mg} / \text { day RT arm } \\
17.5 \% \text { in placebo arm }\end{array}$ \\
\hline Responders rate & $\begin{array}{l}23 \% \text { in } 600 \mathrm{mg} / \text { day RT arm } \\
32 \% \text { in } 900 \mathrm{mg} / \text { day RT arm } \\
33 \% \text { in } 1200 \mathrm{mg} / \text { day RT arm } \\
16 \% \text { in placebo arm }\end{array}$ & $\begin{array}{l}45 \% \text { in } \mathrm{RT} \text { arm } \\
18 \% \text { in placebo arm }\end{array}$ & $\begin{array}{l}31.5 \% \text { in } 600 \mathrm{mg} / \text { day RT arm } \\
39.3 \% \text { in } 900 \mathrm{mg} / \text { day RT arm } \\
17.3 \% \text { in placebo arm }\end{array}$ \\
\hline Adverse events & $\begin{array}{l}\text { Somnolence, confusion, } \\
\text { dizziness, headache, asthenia }\end{array}$ & $\begin{array}{l}\text { Somnolence, dizziness, headache, } \\
\text { confusion, asthenia }\end{array}$ & $\begin{array}{l}\text { Somnolence, dizziness, headache, } \\
\text { confusion, asthenia }\end{array}$ \\
\hline $\begin{array}{l}\text { Open-label } \\
\text { extension }\end{array}$ & $\begin{array}{l}\text { Number of patients: } 222 \\
\text { RT dose: } 900 \mathrm{mg} / \text { day (up to } \\
\text { I } 200 \mathrm{mg} / \text { day) } \\
\text { Median seizure frequency } \\
\text { reduction: } 48.3 \% \\
\text { Responders rate: } 46.4 \% \\
\text { AE: somnolence, confusion, } \\
\text { dizziness, headache, asthenia }\end{array}$ & $\begin{array}{l}\text { Number of patients: I8I } \\
\text { RT dose: } 600-1200 \mathrm{mg} / \text { day (mean dose } \\
\text { I052 mg/day); modification of dose } \\
\text { (of RT and other AEDs) allowed } \\
\text { Duration: } 357 \text { days (trial ongoing) } \\
\text { Median seizure frequency } \\
\text { reduction: } 57 \% \\
\text { Responders rate: } 57 \% \\
\text { Seizure frequency } \\
\text { reduction }>75 \%: 29.6 \% \\
6 \text {-month seizure free period: } 10 \% \\
\text { AE: dizziness, somnolence, urinary } \\
\text { or renal disorders, headache }\end{array}$ & $\begin{array}{l}\text { Number of patients: } 375 \\
\text { RT dose: } 600-1200 \mathrm{mg} / \text { day } \\
\text { (mean dose } 861 \mathrm{mg} / \text { day); } \\
\text { modification of dose (of RT } \\
\text { and other AEDs) allowed } \\
\text { Duration: } 275 \text { days (trial ongoing) } \\
\text { Median seizure frequency } \\
\text { reduction: } 53 \% \\
\text { Responders rate: } 54 \% \\
\text { Seizure frequency } \\
\text { reduction }>75 \%: 24 \% \\
\text { 6-month seizure free period: } 8 \% \\
\text { AE: dizziness, somnolence, } \\
\text { headache, asthenia }\end{array}$ \\
\hline
\end{tabular}

Note: *Not statistically different versus placebo.

Abbreviations: AE, adverse events; RT, retigabine; VP, valproate; CMZ, carbamazepine; PHT, phenytoin; TPR, topiramate; LMT, lamotrigine; GBP, gabapentin; VNS, vagal nerve stimulation.

with no change in the dosage allowed. The maintenance period was 12 weeks, with the possibility to continue with flexible dosing of the drug in an open-label extension of the studies. In both trials, retigabine significantly reduced the median percent in 28-day total partial seizure frequency from baseline (-44\% in the RESTORE $11200 \mathrm{mg}$ /day arm versus $-17.5 \%$ in the placebo group; $-39.9 \%$ in the RESTORE $2900 \mathrm{mg} /$ day and $-27.9 \%$ in the RESTORE 2 $600 \mathrm{mg} /$ day arms versus $-15.9 \%$ in the placebo group). The responder rate from baseline to maintenance phase were also significantly higher than placebo in all the arms considered ( $45 \%$ for $1200 \mathrm{mg} /$ day versus $18 \%$ for placebo; $39.3 \%$ and $31.5 \%$ for $900 \mathrm{mg} /$ day and for $600 \mathrm{mg} /$ day, respectively, versus $17.3 \%$ for placebo). ${ }^{72}$

\section{Safety and tolerability}

The potential toxicity of retigabine was investigated in many preclinical studies conducted in rat and mouse models 
of seizures..$^{57,59,60}$ In general, acute toxicity was limited to dose-related effects on the central nervous system, including hyperkinesia or hypokinesia, disturbed coordination, stilted gait, tremor, and convulsions. ${ }^{72}$ Moreover, retigabine did not exert any toxic effect on cardiac function and on electrocardiographic parameters, but it was able to induce urinary retention, an action explained by the activation of Kv7 channels expressed in smooth muscle of the bladder combined with inhibitory effects on afferent nerve fiber activity. ${ }^{77}$ No teratogenic and/or reproductive effects were observed in rats and rabbits.

In humans, the safety profile of retigabine has been investigated in large Phase II and III (RESTORE 1 and RESTORE 2) trials and their extension studies. In these studies, retigabine was used as additional therapy in patients already receiving 1-3 "classical" antiepileptic drugs. Thus, data concerning the efficacy and safety of retigabine in the form of monotherapy are lacking. As in animal models and similar to other antiepileptic drugs, retigabine showed minor and nonspecific adverse events involving the central nervous system, the most common of which were dizziness, somnolence, headache, and asthenia. These adverse events were generally dose-related, rarely serious, or a cause for discontinuation. Both in Phase II and III clinical trials, a large proportion of them occurred during the forced titration phase, and the proportion of patients withdrawing from the study was inversely related to the duration of the titration phase. ${ }^{2}$ The most common reasons for discontinuation were dizziness, confusion, somnolence, and asthenia, with the highest proportion of withdrawals in patients receiving retigabine $1200 \mathrm{mg} / \mathrm{kg} .{ }^{72}$ In RESTORE 1 , where retigabine was used at $1200 \mathrm{mg} / \mathrm{kg}$, urinary or renal disorders were observed in $12 \%$ of patients. Among urinary disorders, urinary hesitancy was the most frequent adverse event. However, urinary adverse events did not correlate with objective assessments of urinary function, and most patients were able to continue on medication, while in all other patients (except one), this symptom disappeared after discontinuation. Although urinary adverse effects do not seem to be severe, retigabine should be used with caution in patients at risk for urinary dysfunction (benign prostatic hyperplasia, neurogenic bladder), in subjects with cognitive impairment, and in individuals already treated with drugs active on the bladder (anticholinergics) ${ }^{78}$ As suggested by preclinical studies, retigabine did not exert any adverse effects on cardiac function, and did not prolong the QT interval. However, a study of cardiac conduction demonstrated that retigabine produced a slight (on average approximately $4 \mathrm{msec}$ in the 24 hours postdosing) and transient QT-prolonging effect in healthy volunteers receiving $1200 \mathrm{mg} /$ day. Although this extent of QT prolongation may have poor clinical relevance, retigabine should be administered with caution in patients at highest risk for arrhythmia. ${ }^{78}$

\section{Patient-focused perspectives}

Due to the limited clinical experience with retigabine, data regarding quality of life, patient satisfaction, and adherence to therapy are rather scarce. However, the most frequent adverse events related to retigabine are similar to those caused by many other neuroactive drugs, ${ }^{74}$ and they should not worsen quality of life more than other commonly used antiepileptic drugs. Moreover, the clinical relevance of such adverse events as a cause of discontinuation of treatment might be less severe than that predicted by controlled trials because, in these studies, contrary to common clinical practice, little or no adjustment of dose was allowed, thus increasing the rate of treatment-emergent adverse events and of subsequent interruption of therapy. The lack of clinically significant cardiac, hematologic, and hepatic toxicity (which can be associated, although not frequently, with treatment with other antiepileptic drugs, including phenytoin, carbamazepine, or valproate), the inability to induce or inhibit liver enzymes (that can reduce the efficacy of concomitant administered drug and, in particular, of contraceptive therapy), as well as the minimal clinical significance of drug-drug interactions, suggest that retigabine is a well tolerated new antiepileptic drug.

\section{Conclusion}

Nearly $30 \%$ of epileptic patients are resistant to pharmacological treatment, with persistence of frequent seizures despite assumption of one or more antiepileptic drugs. Uncontrolled seizures interfere with daily life, affecting lifespan (increased incidence of injuries and of sudden unexplained death), ${ }^{79}$ and global quality of life (limitations on driving or job availability), causing a condition of "social disability". Pharmacoresistant epilepsy has been associated with increased cognitive impairment ${ }^{80}$ and psychiatric disorders, such as depression. ${ }^{81}$ Despite the availability of several antiepileptic drugs, the probability of obtaining seizure control diminishes progressively with successive antiepileptic drug regimens, and the success of therapy is only $4 \%-7 \%$ on the third drug used or on a combination of two antiepileptic drugs in an add-on regimen. ${ }^{82}$ This reduced efficacy of commonly used medications may, in part, be a consequence of combining drugs with similar mechanisms of action. Moreover, antiepileptic drugs are frequently involved in wide and reciprocal drug-drug interactions, with increased frequency of adverse 
events and subsequent reduced tolerability for patients. ${ }^{83}$ In this context, retigabine, with its different mechanism of action and its broad spectrum of activity demonstrated in numerous seizure and epilepsy models and suggested by Phase II and III clinical trials, could play an important role in the treatment of pharmacoresistant epilepsies. Moreover, retigabine and other neural Kv7 openers may be safe and useful tools for the treatment of pediatric epilepsy. Indeed, the role of $\mathrm{I}_{\mathrm{KM}}$ in reducing neuronal excitability is particularly relevant in early life; due to the excitatory effect of GABAergic neurotransmission in the immature brain, $\mathrm{I}_{\mathrm{KM}}$ represents the main inhibitory conductance in neonatal neurons. ${ }^{84}$ The importance of $\mathrm{I}_{\mathrm{KM}}$ as a "brake" on neuronal excitability in newborns is also suggested by the natural clinical history of benign familial neonatal seizures, in which seizures spontaneously disappear after a few weeks or months, and by several in vitro studies showing that epileptiform activity caused by the pharmacological suppression of $\mathrm{I}_{\mathrm{KM}}$ decreased or disappeared with neuronal maturation. ${ }^{85,86}$ Moreover, it has been demonstrated that, in hippocampal neurons, $\mathrm{I}_{\mathrm{KM}}$ density increased after birth, causing the disappearance of intrinsic bursting and abnormal neuronal synchronization characteristic of the neonatal period. ${ }^{87}$ Based on these data, $\mathrm{I}_{\mathrm{KM}}$ can represent a fascinating therapeutic target for the treatment of neonatal epilepsy, also in consideration of the fact that first-line drugs given to neonates (usually phenobarbital and phenytoin) are effective in less than $50 \%$ of cases $^{88}$ and that they have been demonstrated to cause widespread neuronal apoptosis when given to young rodents, thus raising concerns about their administration to children. ${ }^{89}$ On these premises, flupirtine has been demonstrated to be more effective than phenobarbital and diazepam in arresting kainate- and flurothyl-induced seizures when administered in rats at postnatal day $10 .{ }^{90}$ Moreover, in another study, retigabine has been shown to delay the development of focal seizures in postnatal day 14 rats, and to prevent the establishment of kindling-induced enhanced seizure susceptibility. Interestingly, in the latter study, the effect of retigabine appeared to be more pronounced in younger animals when compared with older ones. ${ }^{91}$ Although these results argue in favor of the use of retigabine also in young children, further investigations are needed to demonstrate the efficacy and safety of this drug in the treatment of seizures occurring at early developmental stages, with special regard to the possible differences in pharmacokinetics (such as the decreased metabolism of retigabine due to the reduced glucuronidation capability of the newborn) which can enhance the frequency and severity of the side effects of retigabine in these patients.

\section{Acknowledgments}

Work on $\mathrm{KCNQ} / \mathrm{I}_{\mathrm{KM}}$ channels in the author's laboratories is currently supported by grants from the European Union (E-Rare 2007, EUROBFNS); Fondazione Telethon Italy (GGP07125); the Italian Ministry of University, Education, and Research (MIUR, PRIN 2007); and Regione Molise (Convenzione AIFA/Regione Molise).

\section{Disclosure}

The authors report no conflicts of interest in this work.

\section{References}

1. Noebels JL. Targeting epilepsy genes. Neuron. 1996;16(2):241-244.

2. Plosker GL, Scott LJ. Retigabine: In partial seizures. CNS Drugs. 2006;20(7):601-608.

3. Forsgren L, Beghi E, Oun A, Sillanpää M. The epidemiology of epilepsy in Europe - a systematic review. Eur J Neurol. 2005;12(4):245-253.

4. Berg AT, Berkovic SF, Brodie MJ, et al. Revised terminology and concepts for organization of seizures and epilepsies: Report of the ILAE Commission on Classification and Terminology, 2005-2009. Epilepsia. 2010;51(4):676-685.

5. Shieh CC, Coghlan M, Sullivan JP, Gopalakrishnan M. Potassium channels: Molecular defects, diseases, and therapeutic opportunities. Pharmacol Rev. 2000;52(4):557-594.

6. Brown DA, Adams PR. Muscarinic suppression of a novel voltagesensitive $\mathrm{K}^{+}$current in a vertebrate neurone. Nature. 1980;283(5748): 673-676.

7. Halliwell JV, Adams PR. Voltage-clamp analysis of muscarinic excitation in hippocampal neurons. Brain Res. 1982;250(1):71-92.

8. Rogawski MA. KCNQ2/KCNQ3 $\mathrm{K}^{+}$channels and the molecular pathogenesis of epilepsy: Implications for therapy. Trends Neurosci. 2000;23(9):393-398.

9. Guo J, Schofield GG. Activation of muscarinic $\mathrm{m} 5$ receptors inhibits recombinant KCNQ2/KCNQ3 $\mathrm{K}^{+}$channels expressed in HEK293T cells. Eur J Pharmacol. 2003;462(1-3):25-32.

10. Marrion NV. Control of M-current. Annu Rev Physiol. 1997;59: 483-504.

11. Delmas P, Brown DA. Pathways modulating neural KCNQ/M (Kv7) potassium channels. Nat Rev Neurosci. 2005;6(11):850-862.

12. Singh NA, Charlier C, Stauffer D, et al. A novel potassium channel gene, KCNQ2, is mutated in an inherited epilepsy of newborns. Nat Genet. 1998;18(1):25-29.

13. Biervert C, Schroeder BC, Kubisch C, et al. A potassium channel mutation in neonatal human epilepsy. Science. 1998;279(5349):403-406.

14. Charlier C, Singh NA, Ryan SG, et al. A pore mutation in a novel KQT-like potassium channel gene in an idiopathic epilepsy family. Nat Genet. 1998;18(1):53-55.

15. Wang Q, Curran ME, Splawski I, et al. Positional cloning of a novel potassium channel gene: KVLQT1 mutations cause cardiac arrhythmias. Nat Genet. 1996;12(1):17-23.

16. Kubisch C, Schroeder BC, Friedrich T, et al. KCNQ4, a novel potassium channel expressed in sensory outer hair cells, is mutated in dominant deafness. Cell. 1999;96(3):437-446.

17. Kharkovets T, Hardelin JP, Safieddine S, et al. KCNQ4, a $\mathrm{K}^{+}$channel mutated in a form of dominant deafness, is expressed in the inner ear and the central auditory pathway. Proc Natl Acad Sci U S A. 2000; 97(8):4333-4338.

18. Iannotti FA, Panza E, Barrese V, Viggiano D, Soldovieri MV, Taglialatela M. Expression, localization, and pharmacological role of Kv7 potassium channels in skeletal muscle proliferation, differentiation, and survival after myotoxic insults. J Pharmacol Exp Ther. 2010;332(3):811-820. 
19. Greenwood IA, Ohya S. New tricks for old dogs: KCNQ expression and role in smooth muscle. Br J Pharmacol. 2009;156(8): 1196-1203.

20. Lerche C, Scherer CR, Seebohm G, et al. Molecular cloning and functional expression of KCNQ5, a potassium channel subunit that may contribute to neuronal M-current diversity. $J$ Biol Chem. 2000;275(29):22395-22400.

21. Brown DA, Passmore GM. Neural KCNQ (Kv7) channels. $B r J$ Pharmacol. 2009;156(8):1185-1195.

22. Cooper EC, Aldape KD, Abosch A, et al. Colocalization and coassembly of two human brain M-type potassium channel subunits that are mutated in epilepsy. Proc Natl Acad Sci U S A. 2000;97(9): 4914-4919.

23. Wang HS, Pan S, Shi W, et al. KCNQ2 and KCNQ3 potassium channel subunits: Molecular correlates of the M-channel. Science. 1998;282(5395):1890-1893.

24. Bellini G, Miceli F, Soldovieri MV, Miraglia del Giudice E, Pascotto A, Taglialatela M. Benign familial neonatal seizures. In: Pagon RA, Bird TC, Dolan CR, Stephens K, editors. GeneReviews [Internet]. Seattle, WA: University of Washington; 1993-2010.

25. Watanabe H, Nagata E, Kosakai A, et al. Disruption of the epilepsy KCNQ2 gene results in neural hyperexcitability. J Neurochem. 2000; 75(1):28-33.

26. Peters $\mathrm{HC}, \mathrm{Hu} \mathrm{H}$, Pongs O, Storm JF, Isbrandt D. Conditional transgenic suppression of $\mathrm{M}$ channels in mouse brain reveals functions in neuronal excitability, resonance and behavior. Nat Neurosci. 2005;8(1): 51-60.

27. Yang Y, Beyer BJ, Otto JF, et al. Spontaneous deletion of epilepsy gene orthologs in a mutant mouse with a low electroconvulsive threshold. Hum Mol Genet. 2003;12(9):975-984.

28. Singh NA, Otto JF, Dahle EJ, et al. Mouse models of human KCNQ2 and KCNQ3 mutations for benign familial neonatal convulsions show seizures and neuronal plasticity without synaptic reorganization. J Physiol. 2008;586(14):3405-3423.

29. Boscia F, Annunziato L, Taglialatela M. Retigabine and flupirtine exert neuroprotective actions in organotypic hippocampal cultures. Neuropharmacology. 2006;51(2):283-294.

30. Otto M, Cepek L, Ratzka P, et al. Efficacy of flupirtine on cognitive function in patients with CJD: A double blind study. Neurology. 2004;62(5):714-718.

31. Friedel HA, Fitton A. Flupirtine. A review of its pharmacological properties, and therapeutic efficacy in pain states. Drugs. 1993;45(4): 548-569.

32. Porter RJ, Nohria V, Rundfeldt C. Retigabine. Neurotherapeutics. 2007; 4(1):149-154.

33. Rundfeldt C. The new anticonvulsant retigabine (D-23129) acts as an opener of $\mathrm{K}^{+}$channels in neuronal cells. Eur J Pharmacol. 1997;336(2-3):243-249.

34. Rundfeldt C. Characterization of the $\mathrm{K}^{+}$channel opening effect of the anticonvulsant retigabine in PC12 cells. Epilepsy Res. 1999;35(2): 99-107.

35. Rundfeldt $C$, Netzer R. The novel anticonvulsant retigabine activates M-currents in Chinese hamster ovary-cells tranfected with human KCNQ2/3 subunits. Neurosci Lett. 2000;282(1-2):73-76.

36. Main MJ, Cryan JE, Dupere JR, Cox B, Clare JJ, Burbidge SA. Modulation of $\mathrm{KCNQ} 2 / 3$ potassium channels by the novel anticonvulsant retigabine. Mol Pharmacol. 2000;58(2):253-262.

37. Wickenden AD, Yu W, Zou A, Jegla T, Wagoner PK. Retigabine, a novel anti-convulsant, enhances activation of KCNQ2/Q3 potassium channels. Mol Pharmacol. 2000;58(3):591-600.

38. Gassen M, Pergande G, Youdim MB. Antioxidant properties of the triaminopyridine, flupirtine. Biochem Pharmacol. 1998;56(10): 1323-1329.

39. Tatulian L, Delmas P, Abogadie FC, Brown DA. Activation of expressed KCNQ potassium currents and native neuronal M-type potassium currents by the anti-convulsant drug retigabine. J Neurosci. 2001;21(15): $5535-5545$.
40. Dupuis DS, Schrøder RL, Jespersen T, et al. Activation of KCNQ5 channels stably expressed in HEK293 cells by BMS-204352. Eur $J$ Pharmacol. 2002;437(3):129-137.

41. Soldovieri MV, Miceli F, Bellini G, Coppola G, Pascotto A, Taglialatela M. Correlating the clinical and genetic features of benign familial neonatal seizures (BFNS) with the functional consequences of underlying mutations. Channels. 2007;1(4):228-233.

42. Peretz A, Degani N, Nachman R, et al. Meclofenamic acid and diclofenac, novel templates of KCNQ2/Q3 potassium channel openers, depress cortical neuron activity and exhibit anticonvulsant properties. Mol Pharmacol. 2005;67(4):1053-1066.

43. Peretz A, Sheinin A, Yue C, et al. Pre- and postsynaptic activation of M-channels by a novel opener dampens neuronal firing and transmitter release. J Neurophysiol. 2007;97(1):283-295.

44. Peretz A, Degani-Katzav N, Talmon M, et al. A tale of switched functions: From cyclooxygenase inhibition to M-channel modulation in new diphenylamine derivatives. PLoS One. 2007;2(12):e1332.

45. Wickenden AD, Krajewski JL, London B, et al. N-(6-chloro-pyridin3-yl)-3,4-difluoro-benzamide (ICA-27243): A novel, selective KCNQ2/Q3 potassium channel activator. Mol Pharmacol. 2008;73(3): 977-986.

46. Roeloffs R, Wickenden AD, Crean $\mathrm{C}$, et al. In vivo profile of ICA27243 [N-(6-chloro-pyridin-3-yl)-3,4-difluoro-benzamide], a potent and selective KCNQ2/Q3 (Kv7.2/Kv7.3) activator in rodent anticonvulsant models. J Pharmacol Exp Ther. 2000;326(3):818-828.

47. Xiong Q, Sun H, Li M. Zinc pyrithione-mediated activation of voltagegated KCNQ potassium channels rescues epileptogenic mutants. Nat Chem Biol. 2007;3(5):287-296.

48. Xiong Q, Sun H, Zhang Y, Nan F, Li M. Combinatorial augmentation of voltage-gated KCNQ potassium channels by chemical openers. Proc Natl Acad Sci U S A. 2008;105(8):3128-3133.

49. Schrøder RL, Jespersen T, Christophersen P, Strøbaek D, Jensen BS, Olesen SP. KCNQ4 channel activation by BMS-204352 and retigabine. Neuropharmacology. 2001;40(7):888-898.

50. Korsgaard MP, Hartz BP, Brown WD, Ahring PK, Strobaek D, Mirza NR. Anxiolytic effects of maxipost (BMS-204352) and retigabine via activation of neuronal Kv7 channels. J Pharmacol Exp Ther. 2005; 314(1):282-292.

51. Bentzen BH, Schmitt N, Calloe K, Dalby Brown W, Grunnet M, Olesen SP. The acrylamide (S)-1 differentially affects Kv7 (KCNQ) potassium channels. Neuropharmacology. 2006;51(6):1068-1077.

52. Wuttke TV, Seebohm G, Bail S, Maljevic S, Lerche H. The new anticonvulsant retigabine favors voltage-dependent opening of the Kv7.2 (KCNQ2) channel by binding to its activation gate. Mol Pharmacol. 2005;67(4):1009-1017.

53. Schenzer A, Friedrich T, Pusch M, et al. Molecular determinants of $\mathrm{KCNQ}(\mathrm{Kv} 7) \mathrm{K}^{+}$channel sensitivity to the anticonvulsant retigabine. J Neurosci. 2005;25(20):5051-5060.

54. Lange W, Geissendörfer J, Schenzer A, et al. Refinement of the binding site and mode of action of the anticonvulsant retigabine on KCNQ $\mathrm{K}^{+}$ channels. Mol Pharmacol. 2009;75(2):272-280.

55. Peretz A, Pell L, Gofman Y, et al. Targeting the voltage sensor of Kv7.2 voltage-gated $\mathrm{K}^{+}$channels with a new gating-modifier. Proc Natl Acad Sci U S A. 2010;107(35):15637-15642.

56. Padilla K, Wickenden AD, Gerlach AC, McCormack K. The KCNQ2/3 selective channel opener ICA-27243 binds to a novel voltagesensor domain site. Neurosci Lett. 2009;465(2):138-142.

57. Rostock A, Tober C, Rundfeldt C, et al. D-23129: A new anticonvulsant with a broad spectrum activity in animal models of epileptic seizures. Epilepsy Res. 1996;23(3):211-223.

58. Dailey JW, Cheong JH, Ko KH, Adams-Curtis LE, Jobe PC. Anticonvulsant properties of D-20443 in genetically epilepsy-prone rats: Prediction of clinical response. Neurosci Lett. 1995;195(2):77-80.

59. de Sarro G, di Paola ED, Conte G, Pasculli MP, de Sarro A. Influence of retigabine on the anticonvulsant activity of some antiepileptic drugs against audiogenic seizures in DBA/2 mice. Naunyn Schmiedebergs Arch Pharmacol. 2001;363(3):330-336. 
60. Tober C, Rostock A, Rundfeldt C, Bartsch R. D-23129: A potent anticonvulsant in the amygdala kindling model of complex partial seizures. Eur J Pharmacol. 1996;303(3):163-169.

61. Postma T, Krupp E, Li XL, Post RM, Weiss SR. Lamotrigine treatment during amygdala-kindled seizure development fails to inhibit seizures and diminishes subsequent anticonvulsant efficacy. Epilepsia. 2000;41(12):1514-1521.

62. Barton ME, Klein BD, Wolf HH, White HS. Pharmacological characterization of the $6 \mathrm{~Hz}$ psychomotor seizure model of partial epilepsy. Epilepsy Res. 2001;47(3):217-227.

63. Srivastava AK, White HS. Retigabine decreases behavioral and electrographic seizures in the lamotrigine-resistant amygdala kindled rat model of pharmacoresistant epilepsy. Epilepsia. 2005;46 Suppl 8:S217.

64. Smith MD, Adams AC, Saunders GW, White HS, Wilcox KS Phenytoin- and carbamazepine-resistant spontaneous bursting in rat entorhinal cortex is blocked by retigabine in vitro. Epilepsy Res. 2007;74(2-3):97-106

65. Straub H, Köhling R, Höhling J, et al. Effects of retigabine on rhythmic synchronous activity of human neocortical slices. Epilepsy Res. 2001;44(2-3):155-165.

66. Hiller A, Nguyen N, Strassburg CP, et al. Retigabine N-glucuronidation and its potential role in enterohepatic circulation. Drug Metab Dispos. 1999;27(5):605-612.

67. Ferron GM, Paul J, Fruncillo R, et al. Multiple-dose, linear, doseproportional pharmacokinetics of retigabine in healthy volunteers. J Clin Pharmacol. 2002;42(2):175-182.

68. Hermann R, Ferron GM, Erb K, et al. Effects of age and sex on the disposition of retigabine. Clin Pharmacol Ther. 2003;73(1):61-70.

69. Hermann R, Borlak J, Munzel U, et al. The role of Gilbert's syndrome and frequent NAT2 slow acetylation polymorphisms in the pharmacokinetics of retigabine. Pharmacogenomics J. 2006;6(3):211-219.

70. Borlak J, Gasparic A, Locher M, Schupke H, Hermann R. N-Glucuronidation of the antiepileptic drug retigabine: Results from studies with human volunteers, heterologously expressed human UGTs, human liver, kidney, and liver microsomal membranes of Crigler-Najjar type II. Metabolism. 2006;55(6):711-721.

71. Ferron GM, Patat A, Parks V, Rolan P, Troy SM. Lack of pharmacokinetic interaction between retigabine and phenobarbitone at steady-state in healthy subjects. Br J Clin Pharmacol. 2003;56(1):39-45.

72. Bialer M, Johannessen SI, Levy RH, Perucca E, Tomson T, White HS. Progress report on new antiepileptic drugs: A summary of the Ninth EILAT Conference (EILAT IX). Epilepsy Res. 2009;83(1):1-43.

73. Hermann R, Knebel NG, Niebch G, Richards L, Borlak J, Locher M. Pharmacokinetic interaction between retigabine and lamotrigine in healthy subjects. Eur J Clin Pharmacol. 2003;58(12):795-802.

74. Porter RJ, Partiot A, Sachdeo R, Nohria V, Alves WM; for 205 Study Group. Randomized, multicenter, dose-ranging trial of retigabine for partial-onset seizures. Neurology. 2007;68(15):1197-1204.

75. Bialer M, Johannessen SI, Kupferberg HJ, Levy RH, Perucca E, Tomson T. Progress report on new antiepileptic drugs: A summary of the Seventh EILAT Conference (EILAT VII). Epilepsy Res. 2004; 61(1-3):1-48.

76. Porter RJ, Nohria V, Pechstein B. Efficacy, safety, and tolerability of retigabine as adjunctive therapy in patients with refractory partial-onset seizures in an open-label study. Epilepsia. 2004;45 Suppl 7:S311.
77. Rode F, Svalø J, Sheykhzade M, Rønn LC. Functional effects of the KCNQ modulators retigabine and XE991 in the rat urinary bladder. Eur J Pharmacol. 2010;638(1-3):121-127.

78. Advisory Committee. Potiga ${ }^{\mathrm{TM}}$ (ezogabine) tablets as adjunctive therapy for the treatment of partial onset seizures. Peripheral and central nervous system drugs. Valeant Pharmaceuticals. 2010 Aug 11. Available from: http://www.fda.gov/downloads/AdvisoryCommittees/ CommitteesMeetingMaterials/Drugs/PeripheralandCentralNervous SystemDrugsAdvisoryCommittee/UCM222587.pdf. Accessed 2010 Nov 8

79. Pati S, Alexopoulos AV. Pharmacoresistant epilepsy: From pathogenesis to current and emerging therapies. Cleve Clin J Med. 2010; 77(7):457-467.

80. Hermann B, Seidenberg M. Epilepsy and cognition. Epilepsy Curr. 2007;7(1):1-6.

81. Kanner AM, Balabanov A. Depression and epilepsy: How closely related are they? Neurology. 2002;58(8 Suppl 5):S2-S39.

82. Kwan P, Sperling MR. Refractory seizures: Try additional antiepileptic drugs (after two have failed) or go directly to early surgery evaluation? Epilepsia. 2009;50 Suppl 8:S57-S62.

83. Brodie MJ. Do we need any more new antiepileptic drugs? Epilepsy Res. 2001;45(1-3):3-6.

84. Okada M, Zhu G, Hirose S, et al. Age-dependent modulation of hippocampal excitability by KCNQ-channels. Epilepsy Res. 2003;53(1-2):81-94.

85. Qiu C, Johnson BN, Tallent MK. $\mathrm{K}^{+} \mathrm{M}$-current regulates the transition to seizures in immature and adult hippocampus. Epilepsia. 2007;48(11): 2047-2058

86. Peña F, Alavez-Pérez N. Epileptiform activity induced by pharmacologic reduction of M-current in the developing hippocampus in vitro. Epilepsia. 2006;47(1):47-54.

87. Safiulina VF, Zacchi P, Taglialatela M, Yaari Y, Cherubini E. Low expression of Kv7/M channels facilitates intrinsic and network bursting in the developing rat hippocampus. $J$ Physiol. 2008;586(22): 5437-5453.

88. Painter MJ, Sher MS, Stein AD, et al. Phenobarbital compared with phenytoin for the treatment of neonatal seizures. $N$ Engl $J$ Med. 1999;341(7):485-489.

89. Olney JW, Young C, Wozniak DF, Jevtovic-Todorovic V, Ikonomidou C. Do pediatric drugs cause developing neurons to commit suicide? Trends Pharmacol Sci. 2004;25(3):135-139.

90. Raol YH, Lapides DA, Keating JG, Brooks-Kayal AR, Cooper EC. A KCNQ channel opener for experimental neonatal seizures and status epilepticus. Ann Neurol. 2009;65(3):326-336.

91. Mazarati A, Wu J, Shin D, Kwon YS, Sankar R. Antiepileptogenic and antiictogenic effects of retigabine under conditions of rapid kindling: An ontogenic study. Epilepsia. 2008;49(10):1777-1786.

92. Miceli F, Soldovieri MV, Lugli L, et al. Neutralization of a unique, negatively-charged residue in the voltage sensor of Kv7.2 subunits in a sporadic case of benign familial neonatal seizures. Neurobiol Dis. 2009;34(3):501-510.

93. Long SB, Tao X, Campbell EB, MacKinnon R. Atomic structure of a voltage-dependent $\mathrm{K}^{+}$channel in a lipid membrane-like environment. Nature. 2007;450(7168):376-382.
Clinical Pharmacology: Advances and Applications

\section{Publish your work in this journal}

Clinical Pharmacology: Advances and Applications is an international, peer-reviewed, open access journal publishing original research, reports, reviews and commentaries on all areas of drug experience in humans. The manuscript management system is completely online and includes a very quick and fair peer-review system, which is all easy to use.

\section{Dovepress}

Visit http://www.dovepress.com/testimonials.php to read real quotes from published authors. 